Vol. 2 No. 3- December 2021

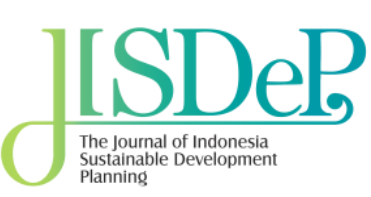

E-ISSN: $\underline{2722-0842}$ | P-ISSN: $\underline{2721-8309}$

Available online at

journal.pusbindiklatren.bappenas.go.id

Book Review

\title{
The Foundation of Social Analysis: Interest Approach
}

\author{
Novri Susan \\ Sociology Department, Universitas Airlangga, Surabaya, Indonesia ${ }^{1}$ \\ novri.susan@fisip.unair.ac.id
}

Introduction

The book entitled 'Interest' is a theoretical elaboration in social sciences written by Richard Swedberg and published by Open University Press in 2005. The book cover is simple, designed with light blue as the cover base, the purple-colored title. Under the title is an illustration of a puzzle that is not yet perfectly formed. The illustration basically hints at an effort of the book in accomplishing the theory of interest. Indeed, throughout the book, Swedberg generally works hard to compile and consolidate the progress of interest as a fundamental concept in social sciences. The book is not directly elaborating or studying about sustainable development studies. However, the theory of interest is obviously helpful in providing a solid perspective in analyzing development issues such as conflict, corruption, policy, and participation.

\section{Interest Theory in Sociology}

The Richard Swedberg's book has five chapters. Chapters 1 and 2 mostly trace the history of interest concept from the nineteenth century or during the industrial revolution in Western Society. Those chapters show the early approach on interest concept, interest as a driving force and a major force. Interest as a driving force means that all humans intrinsically have an interest in their bodies. While as a major force, interest is the result of social dynamic, in which the influence of social structure and interaction contributes to constructing interest. Chapter 3 is the foundation of the approach to the concept of interest from the perspective of the social sciences by elaborating the philosophy of interest among leading scholars from Gustav Ratzenhover, Max Weber, George Simmel, to Pierre Bourdieu. Chapters 1 to 3 are keys to understanding the theoretical approach to interest that Swedberg offers in Chapter 4. Chapter 4 is the original thought of Swedberg that offers a new concept of interest to conduct a social analysis. Chapter 5 is a case of interest analysis as a tool analysis.

\section{ARTICLE INFO}

Received: September 1, 2021

Received in revised form: November 11 , 2021

Accepted: December 29, 2021

\section{JISDeP - The Journal of Indonesia} Sustainable Development Planning Published by Centre for Planners' Development, Education, and Training (Pusbindiklatren),

Ministry of National Development

Planning/ National Development

Planning Agency (Bappenas), Republic of Indonesia
Address: Jalan Proklamasi 70,

Central Jakarta, Indonesia 10320

Phone: +62 $2131928280 / 31928285$

Fax: +62 2131928281

E-mail:

journal.pusbindiklatren@bappenas.go.id

Supported by Indonesian Development Planners Association (PPPI) 
The interesting part of Swedberg's book is his effort in chapter 4 at formulating a new approach of interest as a theory, interest as activity, and interest analogy. However, before discussing the core concepts in Chapter 4, it is necessary to understand the development of the theory of interest in the historical phases of its development from Chapters 1 to Chapter 3 . Briefly, those chapters explain the concepts of interest developed in European society since the industrial revolution era in the 19th century. The philosophical elaboration from Rochefoucauld, David Hume, Adam Smith, Alexis de Tocqueville, Karl Marx, and many others will lead readers to an interesting preliminary analysis of interest. However, at the beginning of its development, the concept of interest was viewed more as material goals or self-interest. In Chapter 3, Swedberg begins elaborating the development of interest from the social sciences perspective, where interest is no longer seen as a material goal and an intrinsic desire. Chapter 3 consists of two perspectives of interest concept led by Gustav Ratzenhover with the concept of interest as a driving force and Max Weber as a major force.

In Chapter 4, Swedberg further clarifies, following the previous chapter, the distinction between the concept of interest in economics and social sciences, including political sciences and sociology. Economics defines interest only as an economic interest or economic self-interest (Swedberg, 2005: 79). Meanwhile, social sciences conceptualize interest with more dimensions rather than only economic interest. However, there is an important intersection between the concepts of interest in economics and social sciences. The interest of an actor is not only generated from an intrinsic want or private interest but social environment such as public pressure.

What is new in Swedberg's thought, among other theories on interest, is to catch the meaning of interest through the analogy of 'following signpost' as the part of 'activity' or 'form of life' (Swedberg, 2005: 96). A signpost is something with a meaning provided by rules, norms, and social values. The analogy of the following signpost indicates that the meaning of interest can be reached in a certain type of activity. There are two conditions of the analogy. First, the actors' decision to choose the direction of a signpost is seen as activities and a physical comprehension of body movement. Therefore, if actors pursue an interest, they will mobilize their bodies at stake. The body movement gives a force and existential dimension to the process of interest realization. Second, the actors of interest have a distinct and special level of consciousness. Each actor has a different way and level of consciousness. In this part of the analogy, that interest is signed by the actors' body movement, not only the mind but also have a special mindset for their activity to result in interest.

The analogy has "three components the actors, the signpost, and the activity of following the direction of signpost" (Swedberg, 2005: 96). Actors can be influenced by other factors such as tradition, habit, and affection, which means that the actors only follow those factors. However, it primarily happens at an early stage of society. When the actors are more aware of their own interests, they try to realize interest intentionally. Therefore, the actors follow the signpost when they know their distinct interest and want to get it. Actors must intentionally orient their behavior to the signpost in which the actors are required to have a decision capacity to follow the signpost or not. At the same time, many signposts exist due to many interests in society such as religion, economic, and love.

Actors are possible to go in many directions by following the signpost. However, private interest will be more difficult to realize than publicly known and acknowledged interest (Swedberg, 2005: 97). An example of this is corruption or anti-corruption action. In an environment dominated by the meaning of interest about bribery as something acknowledged, the interest of anti-corruption will be considered a private interest. Therefore, the actors with the interest of anti-corruption will find it difficult to realize their interests. Another example can be seen in the wasting behavior of a community. When the meaning of interest in wasting behavior or signpost, 'throw trash in the right place' is publicly acknowledged, the actors with private interest that 'throw trash in the wrong place' will have a hard time realizing their interests. The realization of interest, between private interest and public interest, is influenced by the notion that the signpost has a physicality or resistance. Physicality and resistance of signpost, according to Swedberg, signify a force that is out of individual immediate control. Sociologically, the concept of physicality and resistance can be understood as a social structure in the tradition of positivism. A social structure of positivism tradition, such as the theory of structural functionalism of Talcott Parsons, provides what is known as an objective reality that can change the actors' actions.

Signs are not always clear and definite and sometimes can be vague. The vague signpost does not define detailed direction. As an illustration in a daily experience, a driver knows the signpost that instructs to turn left to get an alternative way. However, the signpost does not provide more detail about the map of the road. This is the situation that an actor or driver needs to handle. Inspired by Max Weber 
theory, Swedberg offers a mental disposition composed of distinct awareness and lack of bound feeling. Mental disposition is the capacity to make a decision. A capacity means a readiness to think and act intentionally. Do all actors have a mental disposition? At this concept, generally, researchers in social sciences, including sustainable development studies, can conduct research about related issues. For example, research on women's participation in a village development plan. Do women have mental disposition in the village development plan in the context of patriarchy institution as a signpost? This research can examine whether women's interest has a capacity to follow or even redefine a patriarchal institution during their participation in the village development plan. Participation in this topic is part of women's interest in influencing village development plans.

Last but not least is explaining and understanding how the actors form or create an action to pursue an interest. Since there are many signposts in life, Swedberg does not agree to see interest realization with a single or narrow concept of self-interest. Actions are not merely about the calculation of actors rationally or instrumentally. Actions as an instrumental occur when actors rationally calculate an action as a means to achieve a goal, as in economics called 'cost and benefit analysis.' The reality of a large number of actors in society also illustrates the existence of many signposts. This means that there are many ways in which actions can achieve interests. An interest has its own purpose that is different from other interests. Therefore, the means of action to achieve material and immaterial goals can be different. In addition, each actor has a different mental disposition from one another. Fundamentally, Swedberg implies the need for contextual research from every action related to efforts to realize interests.

The approach of 'activity and analogy' on interest by Richard Swedberg will be a useful perspective for researchers in sustainable development studies. Many issues can be analyzed with this approach to practically recommend a strategic policy, especially in government. The theory of interest by Richard Swedberg also provides a case of interest analysis as a policy tool in Chapter 5 that will help use the theory of interest in many research issues in sustainable development studies.

\section{Conclusions}

The book entitled 'Interest' by Richard Swedberg aims to examine the development of interest theory from the 19th century or the Industrial Revolution era. This book has succeeded in clearly mapping out the theories of interest that have developed. First, interests are analyzed as a 'driving force' and a 'major force'. Second, interest is seen through the concept of self-interest, which is supported by instrumental actions (economics) and non-material actions (socially). Third, a new approach in interest analysis called 'activity and analogy' elaborates the concept of actors, signposts, and activity following signposts.

Why should one read Richard Swedberg's interest analysis approach? The interest analysis approach in the book 'Interest' is a theoretical foundation that is useful for academics and researchers in social science and sustainable development studies. Through the analysis of this approach, academics and researchers are able to understand the underlying problem of why and how actors create an action in certain cases. The results of the interest analysis of cases in sustainable development issues such as environmental issues, governance, participation, and others will provide a policy guide for dealing with issues or formulating new policies.

\section{The Book Rating}

As a foundation of theoretical thought in social sciences, the book 'Interest' is compulsory reading in which many scholars in social sciences can easily comprehend. This book gets five of five stars rating in the author's view. 


\section{The Cover book}

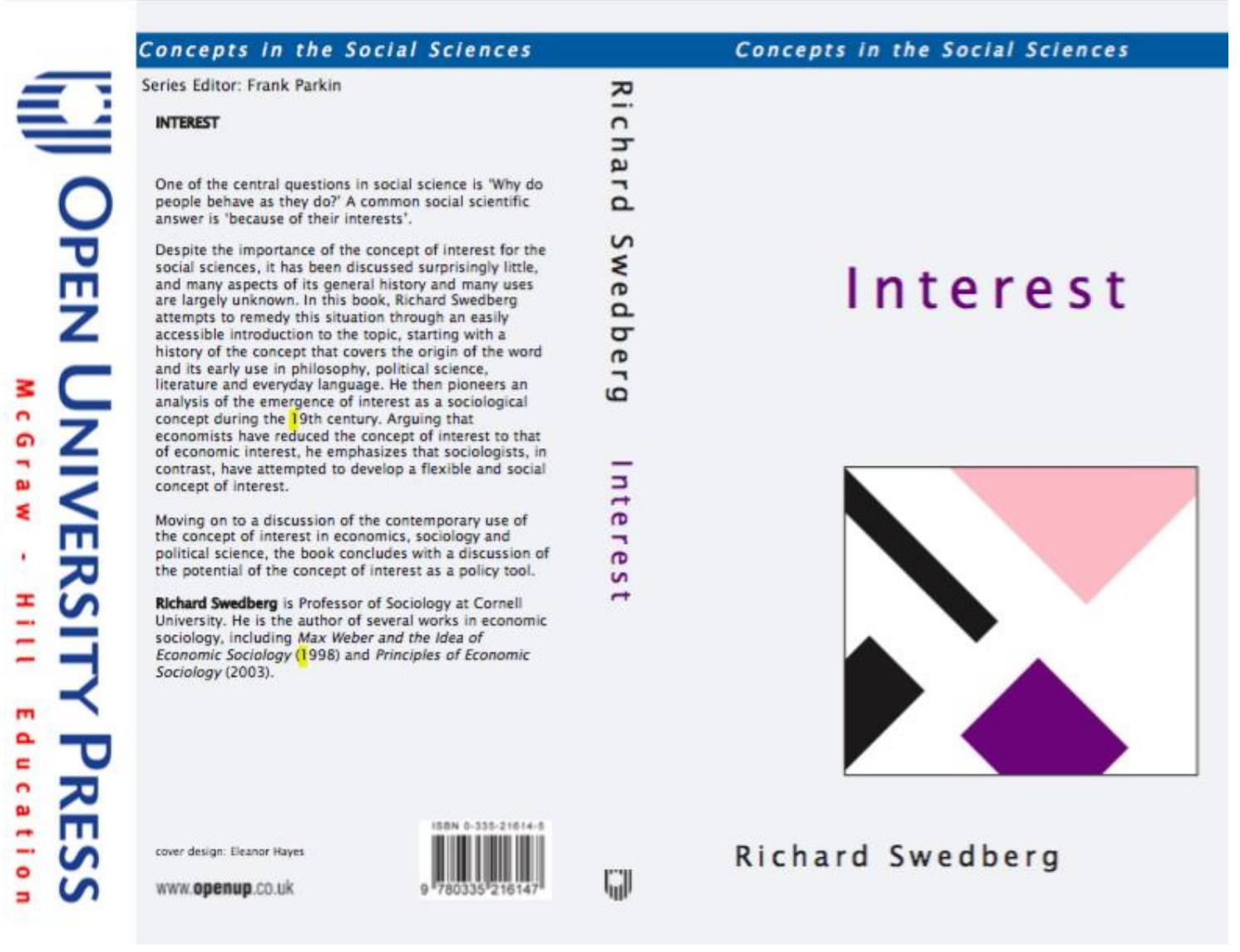

\section{Reference}

Swedberg, Richard. (2005). Interest. Open University Press. 